\title{
Análise de opções reais aplicada na diversificação da produção rural no estado do Paraná
}

\author{
Analysis of real options applied in the diversification of \\ rural production in Paraná state
}

\author{
Wagner Dantas Souza Junior ${ }^{1}$ (D), Juliano Francisco Baldissera ${ }^{1}$ \\ e Geysler Rogis Flor Bertolini ${ }^{1}$
}

Resumo: O presente artigo tem o objetivo de analisar a contribuição do uso da Teoria das Opções Reais (TOR) na análise de investimentos da diversificação da produção rural no estado do Paraná. É uma pesquisa exploratória, com procedimento técnico documental, de caráter quantitativo, utilizando fontes primárias e secundárias, em corte transversal e análise estatística de um estudo de caso sobre a análise da viabilidade financeira e a distruibuição de probabilidades pela TOR em um projeto de investimento de diversificação na produção agrícola. O fluxo de caixa foi baseado em dados de fornecedores e informações coletadas no sítio eletrônico da Secretaria de Agricultura do Estado do Paraná (Seab), em relação ao cultivo das seguintes culturas: café, mandioca, milho, soja e trigo. A análise consistiu no cálculo do valor presente através dos métodos tradicionais de análise de investimento, como o VPL, a TIR e o Payback, e o das opções reais através da árvore binomial para comparabilidade. Os resultados apontam que a Teoria das Opções Reais é um método mais preciso para calcular o valor presente em projetos de diversificação da produção rural, pois capta melhor a flexbilidade gerencial e a movimentação do VPL considerando a volatilidade do projeto.

Palavras-chave: análise de investimentos, teoria das opções reais, agricultura.

Abstract: The objective of this paper is to analyze the contribution of the use of the Real Options Theory (TOR) in the investments analysis of the diversification of rural production in Paraná state (Brazil). It is an exploratory research, with a technical documental procedure, of quantitative character, using primary and secondary sources, in cross-section and statistical analysis of a case study on the analysis of the financial viability and the distribution of probabilities by TOR in an investment project of diversification in agricultural production. The cash flow was based on data from suppliers and information collected on the Secretariat of Agriculture of Paraná State (Seab) website, in relation to coffee, cassava, corn, soybean and wheat crops. The analysis consisted in calculating

Data de submissão: 16 de março de 2017. Data de aceite: 18 de junho de 2018.

1. Universidade Estadual do Oeste do Paraná (UNIOESTE), Cascavel (PR), Brasil. E-mail: wagnerdantas9@gmail.com; juliano.baldissera@hotmail.com; geysler_rogis@yahoo.com.br 
the present value using traditional investment analysis methods such as NPV, TIR and Payback, and the real options through the binomial tree for comparability. The results show that the Real Options Theory is a more accurate method to calculate the present value in projects of diversification of rural production, since it better captures managerial flexibility and the handling of NPV considering project volatility.

Key-words: investment analysis, theory of real options, agriculture.

Classificação JEL: M10, O13, C44.

\section{Introdução}

A globalização e as rápidas alterações acirraram a competitividade empresarial. Nesse contexto, a gestão de investimentos se tornou peça fundamental como instrumento de vantagem competitiva. No entanto, os métodos tradicionais nem sempre dão conta da complexidade gerencial de uma análise de investimento, já que eles não consideram os problemas relacionados à flexibilização gerencial (Macedo \& Nardelli, 2008; Nardelli \& Macedo, 2011).

O Brasil é conhecido internacionalmente pelo potencial produtivo e de exportação de suas commodities agrícolas. A história do País exibe traços de industrialização tardia e de formação de políticas públicas para a expansão e modernização da agroindústria a partir dos anos 50 do século XX. Contudo, o setor enfrenta dificuldades para o seu desenvolvimento e crescimento até os dias atuais, devido, principalmente, à deficiência de recursos necessários para sua capitalização. No entanto, a indústria do agronegócio ainda é a força motriz do desenvolvimento econômico do território nacional. Em 2015, por exemplo, o setor foi responsável pela participação de $21,46 \%$ do Produto Interno Bruto (PIB) nacional. No estado do Paraná, o valor bruto nominal da produção agrícola chegou a quase R\$ 16 bilhões e o PIB per capita foi mais de R\$ 30 mil (Instituto Paranaense de Desenvolvimento Econômico e Social, 2016).

O Paraná tem a agricultura como um dos principais setores econômicos que impulsionaram o seu crescimento ao longo dos anos. O estado já foi considerado o "celeiro agrícola" do País por ter contribuído com uma fração superior a um quarto da produção de matéria-prima para a agroindústria nacional. A estrutura fundiária predominante é de pequenas fazendas, distribuídas pelo território paranaense, predominantemente dominadas por agricultaras familiares, que demonstram capacidade de resistir e resiliência, reassumindo papeis importantes e ensejando a construção de novos modelos de desenvolvimento rural (Baiardi \& Alencar, 2014; Paraná, 2016).

Além disso, o solo fértil e a topografia da região favorecem diversificação na produção agrícola no estado. O potencial produtivo do estado está na cultura de cereais como o milho, o trigo e a soja, que já foram recordistas de safras entre os demais estados brasileiros. Outros produtos que são relevantes na produção são café, arroz, feijão, cana-de-açúcar e fumo. A modernização agrícola do estado também fortaleceu esse processo, por meio da mecanização, eletrificação, irrigação, conservação do solo, uso de fertilizantes e agrotóxicos (Paraná, 2016; Priori et al., 2012).

A diversificação na produção rural é a exploração de diversas culturas na agricultura como uma estratégia para minimizar as incertezas do ambiente de negócios, reduzindo o risco de produzir uma única cultura e ter alto impacto de fatores externos na produção, como o clima, a economia de mercado, pragas e doenças. Com a sua adoção, é possível obter vantagens ambientais e ganhos econômicos diretos e indiretos na redução dos custos de produção, além de reduzir os riscos de se ter apenas uma atividade como principal fonte de renda e manutenção da agricultura familiar (Paraná, 2016). 
Considerando-se a competitividade deste setor, a análise de um projeto de investimento se torna ferramenta fundamental de sobrevivência. No entanto, alguns métodos tradicionais podem não ser suficientes para analisar a realidade de um projeto (Nardelli \& Macedo, 2011). Estes mesmos autores acreditam que considerar uma oportunidade de investimento como uma sucessão de opções de crescimento pode representar uma forma melhor para verificar a viabilidade econômico-financeira de projetos em relação à análise tradicional de investimentos.

Alguns estudos internacionais já buscaram observar a metodologia das opções reais na análise de projeto de investimentos; no entanto, foram direcionados a outros setores econômicos, como o industrial, das empresas extrativistas minerais (Brennan \& Schwartz, 2001; Moel \& Tufano, 2002). Também tiveram estudos nacionais que abordaram essa metodologia, como Evangelista (2006) e Nardelli \& Macedo (2011). Estes autores abordaram essa metodologia, mas não aplicado à produção rural, ou, mais especificamente, na diversificação da produção rural; por isso, percebe-se uma lacuna a ser estudada que merece atenção, o que torna esse trabalho relevante, contribuindo nos contextos teórico e prático.

Para que os agricultores familiares possam diversificar a sua produção de maneira sustentável, beneficiando-se de novos nichos e demandas de mercado pela oferta de diferentes produtos, é preciso o apoio do governo na criação de políticas de desenvolvimento rural, orientação técnica de agentes de desenvolvimento e pesquisa na área do agronegócio, para o aprimoramento dos arcabouços conceitual e metodológico das teorias utilizadas nesta área e para a análise da viabilidade de novas operações. Diante disso, surge a seguinte problemática de pesquisa: Qual a contribuição do uso da Teoria das Opções Reais na análise de investimentos da diversificação da produção rural no estado do Paraná? Para responder a essa questão de pesquisa, estabeleceu-se este estudo com o objetivo de analisar a contribuição do uso da Teoria das Opções Reais na análise de investimentos da diversificação da produção rural no estado do Paraná.

É evidente que, com a diversificação da produção agrícola, a administração da propriedade rural torna-se mais complexa e, portanto, deve-se analisar minuciosamente o fluxo financeiro em uma perspectiva temporal de todas as culturas produzidas inter-relacionadas para verificar a viabilidade financeira das atividades executadas na propriedade.

\section{Referencial Teórico}

\subsection{Agricultura e diversificação da produção rural}

No Brasil, a agricultura sempre teve grande importância dentro do contexto econômico nacional. Com o desenvolvimento do capitalismo, os mercados tornaram-se cada vez mais incertos e dinâmicos, gerando uma crescente complexificação das atividades agrícolas. No cenário que compõe o meio rural, a agricultura familiar é um setor estratégico para garantir a soberania alimentar do País e o desenvolvimento sustentável (Schuch, 2004). Para que a agricultura familiar possa manter-se nesse mercado cada vez mais competitivo e excludente é necessário criar formas alternativas de trabalho e sobrevivência.

A diversificação na produção rural pode ser uma dessas formas. A principal vantagem dessa técnica é a redução dos riscos e incertezas de uma exploração agrícola. Com sua adoção é possível obter ganhos econômicos diretos e indiretos como a redução dos custos de produção e a obtenção de vantagens ambientais. Além disso, reduz o impacto econômico pelo surgimento de crises no setor rural. $\mathrm{O}$ argumento em favor desta afirmação é que um número maior de culturas e/ou criações diminui as variações da renda líquida anual de uma propriedade (Pelinski et al., 2006).

A evolução socioeconômica e do próprio agronegócio percebida nas últimas cinco décadas ocasionou o êxodo rural nestes últimos anos. Com isso, propriedades começaram a perder sua autossuficiência, dependendo cada vez mais de insumos externos, e acabaram se especializando em determinadas áreas. Isso fez com que a administração dessas atividades fosse feita de forma mais adequada, observando instrumento de medição da viabilidade econômico-financeira para determinados investimentos (Araújo, 2005).

A maior parte das atividades rurais se desenvolve de forma irregular durante o exercício fiscal e a administração enfrenta o desafio de reduzir essas irregularidades naturais dessa atividade. Considerando uma perspectiva competitiva para a gestão rural, o administrador rural assume o papel nas atividades relacionadas ao planejamento, controle, processo decisório e avaliação dos resultados, cujo objetivo é a maximização dos resultados (Callado \& Callado, 1999). Valle (1985) comenta que este tipo de entidade se comportará de maneira diretamente 
proporcional com suas dimensões e sua forma econômica da exploração dos seus recursos.

O agronegócio não é uma atividade simples, podendo ser definida, de acordo com Davis \& Goldberg (1957), como a soma das operações de produção e distribuição de suprimentos agrícolas, considerando a própria produção, além de atividades de armazenamento, processamento e distribuição destes produtos agrícolas e derivados. De acordo com Batalha (2005), os produtos agroindustriais são muito variados, consistindo em produtos alimentares ou não, perecíveis ou não, alguns necessitando de processamento complexo. Essa diversidade na produção rural resulta em diferentes tipos de custos que envolvem a produção para cada tipo de produto ou segmento, necessitando de planejamento e controle adequado.

Para transformar uma propriedade especializada em diversificada é necessário que o produtor adquira o hábito de cultivar espécies diferentes em sua propriedade. Para tanto, é necessário preparar as pessoas e máquinas para as mudanças, como realizar um diagnóstico da propriedade identificando seus pontos fortes e fracos; identificar as oportunidades que o mercado oferece e conhecer as exigências dos consumidores. Além disso, é necessário um conhecimento profundo da atividade rural no tocante às suas características, inter-relações e mesmo relacionamentos com os demais setores da economia. Com o diagnóstico, parte-se para a prática. Isto significa a aquisição de máquinas e equipamentos específicos para as novas atividades, adoção de novas tecnologias e de sistemas de produção de acordo com as condições físicas da propriedade. É evidente que, com a diversificação, a administração da propriedade torna-se mais complexa e, portanto, deve haver um equilíbrio entre as atividades executadas na propriedade (Richetti, 2006).

Para se obter o sucesso em uma empresa rural, deve-se observar os aspectos econômicos envolvidos, considerando que o resultado financeiro positivo somente será obtido através de uma tomada de decisão consolidada e apoiada por um sistema de controle ágil e preciso (Franco, 1988). Crepaldi (1993) reconhece as limitações organizacionais e estruturais impostas aos empreendedores rurais e ressalta a importância de gerar informações gerenciais que permitam a tomada de decisão e a escolha de investimentos com base em dados consistentes e reais.
Considerando essa realidade do agronegócio e a dificuldade de planejamento e controle da produção rural, é necessário um aprofundamento nessa matéria. No entanto, utilizar métodos tradicionais podem não gerar as melhores informações na escolha de investimentos, surgindo a necessidade de uso de outros métodos mais sofisticados e modernos. Nesse contexto, na próxima seção objetiva-se o conhecimento destes métodos tradicionais e o método das opções reais.

\subsection{Técnicas de análise de projetos de investimento}

Buscando investigar possíveis métodos de análise de investimentos além daqueles tradicionais que consideram tão somente uma visão estática, abarcamos a visão da Teoria das Opções Reais. A justificativa desta análise está no fato de que a decisão de investimentos é umas das mais importantes para os gerentes financeiros, repercutindo diretamente sobre o resultado econômico-financeiro da empresa por diversos anos (Weston \& Brigham, 2000).

\subsubsection{Métodos tradicionais}

A avaliação de investimentos é objeto de estudo há muito tempo, sendo indicada a adoção de técnicas objetivas para avaliar projetos (Balarine, 2004). Para este artigo serão estudados alguns dos métodos de análise de investimentos mais tradicionais dessa área, como o Valor Presente Líquido (VPL), Taxa Interna de Retorno (TIR) e o Payback.

O Valor Presente Líquido (VPL) é um método de orçamento de capital sofisticada que estima a viabilidade de um projeto de investimento através do desconto dos fluxos de caixas futuros de um projeto a uma taxa de atratividade de investimento especificada (Gitman, 2010). A análise e decisão utilizando o método do VPL consistem, basicamente, em observar se o valor obtido no cálculo foi positivo ou negativo, sendo recomendada a aceitação do projeto no primeiro caso (Mondher, 2002). Algumas críticas são feitas a esse método, pelas falhas em relação ao fluxo de caixa futuro projetado e pelas oportunidades de investimentos implícitas ao projeto, e pelo fato de que ele assume um cenário fixo, sem considerar o valor das contingências e das flexibilidades gerenciais referente às possíveis decisões futuras do projeto (Copeland \& Antikarov, 2001; Dixit \& Pindyck, 2001). 
A Taxa Interna de Retorno (TIR) é entendida como a taxa que iguala o VPL a zero, ou seja, a taxa de juros que atualiza uma série de rendimentos futuros de um projeto e a iguala ao valor do investimento inicial (Ross et al., 1998; Casarotto Filho \& Kopittke, 2000). A TIR é utilizada para comparar alternativas de investimentos em projetos, normalmente feita com uma Taxa Mínima de Atratividade (TMA), que é uma taxa que o investidor considera como o mínimo de retorno que ele pretende com determinado investimento. Quando a TIR for maior que a TMA, o projeto deveria ser aceito e, sendo igual ou menor, o projeto deveria ser rejeitado. Da mesma forma que o VPL, algumas críticas são feitas ao método da TIR. Uma delas é feita por Casarotto Filho \& Kopittke (2000), que afirmam que existem possibilidades de determinados investimentos admitirem a existência de múltiplas TIRs. Outra crítica é feita por Gitman (2010), que comenta que o emprego deste método pressupõe o reinvestimento de valores à taxa determinada pela própria TIR.

O método payback descontado é o mais simples e, justamente por isso, muito utilizado. O payback é entendido como o período de tempo necessário para recuperar o capital investido, isto é, o tempo necessário para que os seus benefícios advindos do investimento possam cobrir os custos a uma TMA adequada (Gitman, 2010).

Portanto, percebe-se que cada um dos métodos citados, pela sua simplicidade, geram diversas limitações e críticas para sua utilização e, por isso, é necessário que a análise de investimentos seja feita considerando não tão somente estes métodos, buscando, também, outras alternativas que retratem melhor a realidade da empresa, e um destes é o método das opções reais.

\subsubsection{Método das opções reais}

No mercado financeiro, o termo opção é um instrumento que confere ao titular a oportunidade de comprar ou vender um ativo específico, a um determinado preço, em uma data de vencimento estipulada (Opção Europeia), ou antes dela (Opção Americana). Já a expressão opções reais remete a oportunidades implícitas em projetos de capital que permitem aos administradores alterar os fluxos de caixa e seus riscos de maneira a afetar a aceitabilidade (VPL) do projeto (Gitman, 2010). Ao reconhecer explicitamente essas opções na tomada de decisões de orçamento de capital, os administradores podem tomar decisões mais estratégicas que levem em consideração o impacto econômico de atos contingenciais sobre o fluxo de caixa e o risco do projeto (Gitman, 2010).

Os métodos de precificação de opções são ferramentas promissoras na análise de questões estratégicas, principalmente em situações relacionadas à interdependência sequencial entre projetos, consistindo em uma ferramenta adequada ao gestor para auxiliar a tomada de decisão e resolver o problema convenientemente. Inclui a flexibilidade gerencial na análise e tomada de decisões de investimentos (Trigeorgis \& Mason, 1987; Myers, 1987; Zilio \& Lima, 2015). Portanto, percebe-se que projetos não necessariamente devem ser mantidos, como se considera nos métodos tradicionais, quando forem observadas situações adversas ao planejamento inicial.

Segundo Myers (1987), considerar a oportunidade futura como um segundo estágio do investimento inicial, estimar os fluxos de caixa proporcionados pelos estágios e descontá-los junto à taxa de desconto específica podem não levar à resposta correta. Portanto, este segundo estágio é um momento de opção para empresa, pois se avalia novamente o projeto e, se o mesmo for viável, pode ser continuado ou descontinuado. Trigeorgis \& Mason (1987) consideram que o cálculo convencional de VPL pode subestimar projetos quando ignora o prêmio da opção, sendo que esta subavaliação pode ser quantificada pela Teoria das Opções Reais (TOR). A TOR auxilia, por isso, na quantificação dos riscos, a partir de uma perspectiva financeira, a qual estabelece o valor das opções estratégicas (Sousa Neto et al., 2008). Portanto, este método indica que o valor estratégico de um investimento pode ser quantificado pelo valor do prêmio de opção que a flexibilidade gerencial proporciona ao investimento. A fórmula do VPL expandido é a soma do VPL tradicional com o valor da flexibilidade gerencial.

Em projetos agropecuários existe muita incerteza quanto ao preço futuro das commodities relacionadas, afetando diretamente o retorno do investimento esperado. A variação desse mercado é constante e o VPL pode ser positivo em um determinado investimento; no entanto, no futuro essa mesma realidade já pode ter sido alterada (Nardelli \& Macedo, 2011).

A técnica do VPL subestima o valor da flexibilidade do negócio, ao contrário das opções reais, que apresentam maior valor quando três fatores se combinam 1) grande incerteza quanto ao futuro; 2) muito espaço para a flexibilidade gerencial e 3) quando o VPL sem flexibilidade está próximo de zero (Copeland \& Antikarov, 2001). 
As variáveis encontradas na relação entre as opções financeiras e as opções reais e que são observadas e identificadas prontamente nos projetos de investimentos são: o valor do investimento no projeto, a taxa de juros livre de risco, os períodos do projeto e o valor presente. A variável volatilidade, contudo, não se apresenta de uma forma simplificada, devendo ser calculada ou estimada a partir de alguns elementos ou parâmetros que confiram confiabilidade ao estudo. A importância da volatilidade de um ativo é que ela representa o percentual de risco existente no próprio negócio. A avaliação da volatilidade de um ativo é determinada pelo desvio padrão da evolução histórica dos retornos dos preços do ativo subjacente, sendo expressa, normalmente, em valores percentuais (Evangelista, 2006).

A implementação de um modelo baseado na TOR inicia-se pela determinação do valor do ativo subjacente, em que para tanto, normalmente, se utiliza o VPL (Brasil et al., 2011; Zilio \& Lima, 2015). O investidor tem a opção de adiar, alterar a escala, abandonar, alternar o uso e aguardar a queda do custo de capital (Zilio \& Lima, 2015). Essa flexibilidade gerencial existente torna a curva do VPL em um formato assimétrico, uma vez que as decisões são tomadas de forma a maximizar os retornos do projeto nos $n$ instantes do tempo (Trigeorgis, 2002; Zilio \& Lima, 2015).

O estudo de mercado geralmente é um dos primeiros itens a serem avaliados quando da elaboração de projetos. Por isso, as oscilações deveriam ser analisadas, assim como os riscos e as incertezas desse mercado e também os períodos futuros, que vão além dos pré-estabelecidos pelas análises tradicionais do VPL (Evangelista, 2006).

A construção da árvore binomial é uma técnica útil e popular para precificar uma opção sobre uma ação, permitindo a análise de desenvolvimento durante toda a sua trajetória de vida (Hull, 1996). Há dois tipos de técnicas numéricas para avaliação de opções, as quais tomam como referência o trabalho seminal de Black \& Scholes (1973): (1) obtém-se o valor sobre o processo estocástico direto; (2) obtém-se o resultado aproximado de uma equação diferencial parcial (Trigeorgis, 2002). Existem três vantagens para o modelo de avaliação de opções binomiais: (1) permite ordenar os períodos de aplicações de opções reais, incluindo nessa alguma complexidade; (2) retém a aparente análise do fluxo de caixa descontado; (3) a incerteza e as consequências de decisões contingentes são dispostas de um modo natural
(Amram \& Kulatilaka, 1999). Portanto, o modelo binomial pode facilitar a análise de projeto de investimentos gerando boas imagens visuais.

A técnica das opções se orienta pelo modelo binomial, que determina os nós de decisões. O primeiro período se inicia pelo ativo subjacente (V0), que normalmente é o valor do VPL, Supondo-se que ocorra grau de elevação (u) no ativo subjacente, consequentemente há uma descida (d) para o mesmo ativo. Ao se multiplicar o ativo pelo seu valor de subida ou descida, obtém-se o valor ativo para o próximo nó, e assim por diante. Esses indicadores são estabelecidos pelas Fórmulas 1 a 3:

$u=e^{\sigma \sqrt{ } \Delta t}$

Na qual:

$e=$ número " $\mathrm{e}^{\text {" }}$

$\sigma=$ volatilidade (risco) do ativo

$\Delta t=$ intervalo de tempo

$d=e^{-\sigma \sqrt{ } \Delta t}$

$a=e^{r f \Delta t}$

Na qual:

$d=$ movimento descendente (expressão "down" em inglês)

$a=$ movimento ascendente do ativo (expressão "up" em inglês)

$r f$ = taxa de juros livre de risco

Para se obter a probabilidade de ocorrência de um movimento ascendente utiliza-se a seguinte Fórmula 4:

$p=\frac{a-d}{u-d}$

Já a probabilidade para um movimento descendente ocorrer igual a (q) conforme a Fórmula 5:

$q=1-p$

Na qual:

$p=$ probabilidade

Mondher (2002) argumenta que a estrutura de avaliação de ativos reais baseou-se no modelo binomial clássico de Cox, Ross e Rubinstein, de 1979, no qual o preço dos ativos subjacentes sobe $(\mathrm{u})$ ou desce $(\mathrm{d})$, com uma probabilidade $p$ e $q=1-p$. Na Figura 1 é ilustrado o modelo binomial utilizado em estudos de opções reais.

A Figura 1 apresenta o modelo da árvore binomial recombinante, utilizado em opções reais, na qual a vida do projeto é subdivida em $t$ intervalos de períodos de tempo, denominado $\Delta t$. A cada um dos períodos o valor 
Figura 1. Modelo binomial utilizado em opções reais



Fonte: Copeland \& Antikarov (2001).

inicial (V0) se divide em dois valores, assumindo posição superior (movimento ascendente $S u$, probabilidade $p$ ) ou inferior (movimento descendente $S d$, probabilidade 1- $p$ ) (Evangelista, 2006).

Assim, esta técnica visa estimar o retorno do investimento do projeto através de uma distribuição de probabilidades ao longo dos nós, considerando o custo-benefício dos retornos gerados pelo VPL associados às decisões gerenciais tomadas no tempo, para poder decidir a continuidade ou não do projeto ao longo de cada período. Portanto, a aplicação da TOR se mostra pertinente no ambiente do agronegócio, uma vez que apresenta todas as condições para a implementação da técnica de análise, permitindo uma conclusão mais realista sobre a viabilidade econômico-financeira de projetos de investimento, como seria o caso da diversificação da produção rural (Nardelli \& Macedo, 2011).

\subsection{Estudos anteriores}

Outros estudos internacionais já buscaram analisar o método das opções reais em determinados segmentos, e alguns destes foram aplicados em empresas extrativistas minerais - isso foi verificado nos estudos de Brennan \& Schwartz (2001) e Moel \& Tufano (2002). Estudos nacionais também fizeram essa abordagem, considerando cooperativas de crédito, como foi o estudo de Evangelista (2006), e também considerando um projeto agroindustrial, no estudo de Nardelli \& Macedo (2011).
Brennan \& Schwartz (2001) desenvolveram uma metodologia para avaliar projetos de mineração por meio das opções reais, fazendo uso das opções de iniciar, paralisar a lavra, ou manter as operações mínimas ou a um nível de manutenção. Este artigo demonstrou como os ativos cujos fluxos de caixa dependem de preços de saída altamente variáveis podem ser avaliados e como as políticas ótimas para gerenciá-los podem ser determinadas explorando as propriedades de replicação de carteiras de autofinanciamento. Percebe-se que, apesar de o estudo destes autores ser relacionado à uma atividade diferente da rural, a realidade destes negócios se assemelha, já que trabalham com valores de saída, como é o caso de produtos relacionados à mineração e à commodities.

Moel \& Tufano (2002) estudaram a técnica das opções reais no enfoque de abertura e fechamento de minas. Utilizando uma base de dados de 285 minas de ouro norte-americanas no período de 1988 a 1997, descobriram que o modelo das opções reais é um descritor útil das decisões de abertura e fechamento das minas. Além disso, ficou claro que a decisão de fechar uma mina está relacionada a fatores gerenciais específicos de uma empresa que normalmente não são considerados dentro de um modelo de opções reais restrito.

Evangelista (2006) realizou um estudo de caso em uma cooperativa de crédito comparando a análise de investimentos entre o método VPL e o de opções reais. Este estudo concluiu que o método de VPL 
tradicional é importante e continua a ser fundamental para a determinação da utilização do método de opções reais, evidenciando-se que o método de opções reais complementa e amplia a análise de investimentos em projetos estudados pelo método do VPL tradicional.

Nardelli \& Macedo (2011) analisaram a viabilidade econômico-financeira de um projeto agroindustrial por meio da TOR. O resultado obtido pelos autores demonstrou que o VPL expandido do projeto, considerando-se as opções reais, teve aumento de $207 \%$ em relação ao VPL tradicional.

Portanto, o estudo deste método na diversificação rural, principalmente em commodities no estado do Paraná, é uma lacuna de pesquisa ainda não explorada, sendo importante para análise dessa realidade, contribuindo com pesquisas futuras e para o próprio conhecimento dos usuários dessa informação. De modo a estabelecer os procedimentos metodológicos escolhidos para o desenvolvimento dessa pesquisa, tem-se a próxima seção.

\section{Metodologia}

Para obter uma resposta do problema e atingir o objetivo de pesquisa, é necessário delinear uma metodologia de pesquisa adequada para os fins propostos. Como esta pesquisa pretendeu analisar o impacto que o método das opções reais da análise de investimentos tem sobre a diversificação da produção rural, foi necessário definir uma tipologia de estudo adequada.

Assim, esta pesquisa classificou-se como exploratória quanto aos objetivos, já que se pretende analisar, descrever e comparar os resultados obtidos através dos métodos de investimentos tradicionais e os das opções reais para verificar o valor das flexibilidades gerenciais implícitas. A pesquisa exploratória aborda um assunto ainda não muito estudado e sua principal finalidade é desenvolver, esclarecer e modificar conceitos e ideias, sendo orientado a descobertas, o que corrobora com os objetivos desta pesquisa (Gil, 2009).

Quanto aos procedimentos, é classificado como uma pesquisa documental, já que se utilizou dos dados obtidos do portal eletrônico da Seab para estimar as receitas e despesas do projeto e de cotações de empresas para compor o nível de investimento inicial, em que se analisou e descreveu os métodos de análise de investimento.
A classificação deste estudo como pesquisa documental se justifica pelo fato de utilizar materiais que ainda não receberam um tratamento analítico (Gil, 2009) e sua importância está relacionada à capacidade de organizar informações que estão dispersas, dando-lhes uma nova importância, tendo seu mérito para verificar fatos passados, os quais podem ser úteis, e também identificar o presente e apresentar tendências futuras (Beuren, 2009). E, por fim, quanto à abordagem do problema, trata-se de um estudo quantitativo, pois se utilizou de técnicas estatísticas e de análise de investimentos para observar o método das opções reais frente aos demais métodos.

Esta pesquisa foi realizada a partir da coleta de dados de fontes secundárias no sítio eletrônico da Secretaria da Agricultura e do Abastecimento do Estado do Paraná (SEAB). Os dados coletados referem-se a uma estimativa das receitas e despesas necessárias para a produção dos hortifrutigranjeiros cutivados na agricultura do estado, em função da relevância econômica no consumo interno e na exportação do estado. Todos os produtos têm a sua produtividade influenciada pela estacionalidade, então foram considerados os dados da sua primeira safra, ou safra principal, para estimar a produtividade média por hectare.

Todos os dados foram coletados, organizados e registrados no software Microsoft Excel ${ }^{\circledR}$. Em seguida, metodologicamente, projetou-se no software os fluxos de caixa futuros do projeto em um período de tempo de 10 anos, foram estimados os métodos tradicionais de investimento VPL, TIR e payback e o método das opções reais para comparar a tomada de decisão da análise de investimento pelos métodos utilizados. A análise dos resultados é feita de forma descritiva e comparativa, a fim de verificar se o método das opções reais contribui para a tomada de decisão nos projetos de diversificação da produção rural.

Ressalta-se que esta pesquisa foi realizada em 2016, com a utilização de dados do mesmo período obtidos no site do Seab e, justamente por se tratar de uma pesquisa documental, tem a limitação dos dados disponíveis nessas fontes, além do tempo necessário para o desenvolvimento do estudo, que não permitiu a análise de um contexto maior, considerando uma amostra diferente. No entanto, ainda com essas limitações, a pesquisa tem valor científico e técnico, já que aborda um tema ainda pouco explorado, que é o método das opções reais, sendo inovador por analisar a diversificação 
da produção rural sob a ótica dessa teoria no contexto da análise de projeto de investimentos. Portanto, o delineamento dessa pesquisa permitiu a descrição e análise dos resultados, apresentado na próxima seção.

\section{Descrição e análise dos resultados}

O projeto de investimento de diversificação na produção rural proposto consiste na produção de seis culturas agrícolas diferentes em uma pequena fazenda na região oeste do estado do Paraná. Esta região foi escolhida pela permissão do cultivo das culturas selecionadas em função do zoneamento agrícola, da topografia, do clima e características do solo favoráveis ao cultivo de grãos e raízes. O tamanho da área projetada a ser cultivada é de 24 hectares, ou aproximadamente 10 alqueires, em 10 anos. Este tamanho de área corresponde a uma pequena propriedade rural de agricultura familiar na região. As culturas escolhidas foram: café, feijão, mandioca, milho, soja e trigo.

$\mathrm{O}$ dimensionamento do solo e a distribuição dos cultivares neste estudo de caso foram realizados de acordo com a estacionalidade das culturas e possibilidade de rotatividade das safras para manter a conservação do solo. A mandioca foi distribuída em uma área de três hectares e a sua produção e colheita se dão anualmente, através de ciclos. O plantio do café ocorre no período de setembro a maio e a colheita, de maio a novembro, em uma safra anual, não sendo possível rotacionar esta cultura nos períodos subsequentes utilizando o mesmo solo. A safra de feijão é versátil, com um ciclo curto de desenvolvimento entre 70 e 110 dias, e o período previsto para plantio foi entre fevereiro e abril. Para rotacionar esta cultura foi selecionado o trigo, por ser uma cultura de inverno que tem plantio e colheita entre maio e setembro, e que neutraliza a contaminação do solo. Após esta colheita, foram selecionadas a soja e o milho, dividindo-as em nove hectares para cada uma. O início do plantio destas culturas é em setembro e a colheita, entre janeiro e fevereiro.

O investimento inicial deste tipo de empreendimento consiste no volume financeiro a ser dispendido para iniciar a operação das atividades. Para começar este tipo de empreendimento é necessário ter posse da terra para o cultivo, que pode ser própria ou arrendada, maquinários para preparar o solo, iniciar o plantio e colher - em função do tamanho da área estimada -, e um meio de transporte para levar o produto colhido até o local para armazenamento dos produtos, os quais também podem ser próprios ou terceirizados. Além disso, é necessário ter recursos em caixa como capital de giro, para financiar a operação nos períodos entre o plantio e a colheita e, também, recursos como reserva técnica, para demonstrar liquidez perante aos bancos e obter o seguro da operação, em caso de externalidades climáticas e possível perda da colheita.

Algumas premissas foram adotadas neste projeto: a terra para plantio (10 alqueires) é de propriedade do produtor ou de sua família; a estrutura de capital é formada apenas pelo capital próprio do produtor, não considerando o financiamento dos investimentos, o máquinário será adquirido pelo produtor; o capital de giro inicial será de $10 \%$ do valor das máquinas e utensílios agrícolas; e a reserva técnica, que é a poupança da empresa, será de $5 \%$ do valor total das máquinas e utensílios. Após a colheita, o transporte e o armazenamento dos produtos até o silo da indústria deve ser terceirizado pela mesma, pois é uma prática da região, e o seu cálculo foi embutido junto à despesa anual.

As máquinas e implementos agrícolas para viabilizar a operação deste projeto são: 1 trator, 1 colheitadeira, 1 plantadeira, 1 semeadeira, 1 bomba d'água, 1 bomba de graxa, 1 bazuca para adubo e 1 pulverizador para veneno. $\mathrm{O}$ investimento total com maquinário e utensílios foi estimado em $R \$ 610.500$; o capital de giro, em $R \$$ 61.050, $10 \%$ sob o valor total do maquinário; e a reserva técnica, em $\mathrm{R} \$ 30.525,5 \%$ do valor total do maquinário. $\mathrm{O}$ investimento total para iniciar as operações é de R \$ 702.075. Os valores que compõem o investimento inicial foram estimados com base em cotações do mercado local (PR). Na Tabela 1, apresentam-se os itens que compõem o aporte inicial.

Para estimar as receitas de vendas anuais de cada cultura, é necessário obter o preço unitário de cada produto e multiplicar pela quantidade anual produzida. Utilizou-se como base o preço mensal de cada cultura e a produtividade média por hectare em outubro de 2016 disponibilizados pela Secretaria de Agricultura e Abastecimento do Estado do Paraná (Seab). Calculou-se ano após ano, em um horizonte de 10 anos, a projeção de receitas. Em seguida, corrigiram-se os valores nos períodos futuros com base na média do índice de inflação 
IGP-M dos últimos 12 meses anteriores a outubro de 2016, que foi de 7,13\%. O total da receita estimada no ano 1, por exemplo, foi de R\$350.016. No médio prazo do projeto, no $5^{\circ}$ período, por exemplo, a receita alcança $\mathrm{R} \$ 461.033$. Ao final do projeto, no $10^{\circ}$ período, estima-se receita total anual de $\mathrm{R} \$ 650.560$. Os resultados estão apresentados na Tabela 2.

Para projetar as despesas e o custo total de produção de cada cultura, foram utilizados como referência os dados da SEAB (Paraná, 2016). A composição do custo variável deste tipo de projeto constitui-se pelos seguintes itens: operação de máquinas e implementos agrícolas, despesas de manutenção de benfeitorias, mão de obra temporária, sementes e manivas, fertilizantes, agrotóxicos, despesas gerais, transporte externo, assistência técnica, seguro/proagro e os juros sobre o capital. O custo variável também é chamado de custo operacional, pois varia em função da quantidade produzida na operação.
Os custos fixos na produção agrícola são a depreciação de máquinas e implementos, depreciação de benfeitorias e instalações, sistematização e correção do solo e a remuneração pela terra. São os custos que não têm alteração relevante de valor em caso de aumento ou diminuição da produção.

O valor de cada item do custo médio total dos produtos foi calculado e projetado com base na média de custo unitário dos últimos dois anos (ou cinco safras) de cada produto agrícola. A Tabela 3 detalha o custo médio por cultura por safra:

Após obter o valor do custo médio total de cada produto por safra/ano, realizou-se a projeção do custo total do projeto para os próximos 10 períodos, que é o período estabelecido para depreciação das máquinas e implementos e benfeitorias e instalações, conforme estabelece a Instrução Normativa SRF n. 162/1998 da Receita Federal do Brasil (1990). Para obter estes valores,

Tabela 1. Descrição dos itens que compõem o investimento inicial (em Reais)

\begin{tabular}{lcrc}
\hline \multicolumn{1}{c}{ Descrição Item } & Quantidade & Valor & Total \\
\hline Máquinas e Utensílios Agrícolas & 1 & & 610.500 \\
Trator & 1 & 150.000 & 150.000 \\
Colheitadeira & 1 & 390.000 & 390.000 \\
Semeadeira para trigo & 1 & 25.000 & 25.000 \\
Plantadeira para milho e soja & 1 & 25.000 & 25.000 \\
Bomba d'água & 1 & 2.000 & 2.000 \\
Bomba de graxa (engraxadeira) & 1 & 1.500 & 1.500 \\
Bazuca para adubo (12 toneladas) & 1 & 12.000 & 12.000 \\
Pulverizador para veneno & & 5.000 & 5.000 \\
SUBTOTAL & & & $\mathbf{6 1 0 . 5 0 0}$ \\
Capital de Giro (10\%) & & & 61.050 \\
Reserva Técnica (5\%) & & 30.525 \\
Investimento Inicial Total & & & 702.075 \\
\hline
\end{tabular}

Tabela 2. Projeção Anual de Receitas por Cultura (em Reais)

\begin{tabular}{lrrrrrrrrrrr}
\hline \multicolumn{1}{c}{ Produto } & Ano 1 & \multicolumn{1}{c}{ Ano 2 } & \multicolumn{1}{c}{ Ano 3 } & \multicolumn{1}{c}{ Ano 4 } & Ano 5 & Ano 6 & Ano 7 & Ano 8 & Ano 9 & Ano 10 \\
\hline Café & 58.993 & 63.200 & 67.706 & 72.533 & 77.705 & 83.245 & 89.181 & 95.539 & 102.351 & 109.649 \\
Feijão & 141.488 & 151.577 & 162.384 & 173.962 & 186.365 & 199.653 & 213.889 & 229.139 & 245.476 & 262.979 \\
Mandioca & 38.377 & 41.114 & 44.045 & 47.186 & 50.550 & 54.154 & 58.015 & 62.152 & 66.583 & 71.331 \\
Milho & 43.350 & 46.441 & 49.752 & 53.299 & 57.099 & 61.171 & 65.532 & 70.204 & 75.210 & 80.572 \\
Soja & 35.043 & 37.542 & 40.218 & 43.086 & 46.158 & 49.449 & 52.975 & 56.752 & 60.798 & 65.133 \\
Trigo & 32.763 & 35.100 & 37.602 & 40.283 & 43.155 & 46.232 & 49.529 & 53.060 & 56.843 & 60.896 \\
Total Anual & $\mathbf{3 5 0 . 0 1 6}$ & $\mathbf{3 7 4 . 9 7 2}$ & $\mathbf{4 0 1 . 7 0 8}$ & $\mathbf{4 3 0 . 3 4 9}$ & $\mathbf{4 6 1 . 0 3 3}$ & $\mathbf{4 9 3 . 9 0 5}$ & $\mathbf{5 2 9 . 1 2 0}$ & $\mathbf{5 6 6 . 8 4 7}$ & $\mathbf{6 0 7 . 2 6 3}$ & $\mathbf{6 5 0 . 5 6 0}$ \\
\hline
\end{tabular}

IGP-M Out/2016 acumulado últimos 12 meses = 7,13\%. Fonte: Elaborado pelos autores. 
Tabela 3. Projeção do Custo Total do período por cultura (em Reais).

\begin{tabular}{|c|c|c|c|c|c|c|c|}
\hline & Custo Médio de Produção por Cultura & Café & Feijão & Mandioca & Milho & Soja & Trigo \\
\hline $0-$ & Área Produzida & 3ha & 18ha & 3ha & 9ha & 9ha & 18ha \\
\hline $1-$ & Operação de máquinas e implementos & 1.902 & 1.752 & 1.007 & 2.575 & 2.559 & 5.528 \\
\hline $2-$ & Despesas de manutenção de benfeitorias & 222 & 1.104 & 157 & 275 & 300 & 420 \\
\hline $3-$ & Mão de obra temporária & 30.077 & 544 & 7.600 & 285 & 345 & 760 \\
\hline $4-$ & Sementes/Manivas & - & 5.451 & 560 & 6.051 & 3.088 & 3.770 \\
\hline $5-$ & Fertilizantes & 8.485 & 9.382 & 1.020 & 9.075 & 3.987 & 11.099 \\
\hline $6-$ & Agrotóxicos & 9.682 & 12.979 & 679 & 2.079 & 3.769 & 8.120 \\
\hline 7 - & Despesas gerais & 1.021 & 769 & 230 & 406 & 261 & 594 \\
\hline $8-$ & Transporte externo & 582 & 874 & 1.716 & 2.039 & 801 & 1.398 \\
\hline $9-$ & Assistência técnica & 1.042 & 785 & 234 & 418 & 287 & 607 \\
\hline $10-$ & Proagro/Seguro & 989 & 964 & - & 610 & 422 & 888 \\
\hline \multirow[t]{2}{*}{11 - } & Juros & 2.339 & 1.118 & 253 & 706 & 653 & 1.090 \\
\hline & TOTAL DOS CUSTOS VARIÁVEIS (A) & 56.342 & 35.722 & 13.455 & 24.517 & 16.472 & 34.275 \\
\hline $12-$ & Depreciação de máquinas e implementos & 902 & 912 & 497 & 2.218 & 2.057 & 4.686 \\
\hline $13-$ & Depreciação de benfeitorias e instalações & 309 & 1.218 & 82 & 401 & 400 & 558 \\
\hline \multirow[t]{2}{*}{$14-$} & Sistematização e correção do solo & 1.100 & 1.298 & 1.153 & 658 & 659 & 1.320 \\
\hline & SUB-TOTAL (B) & 2.311 & 3.428 & 1.732 & 3.276 & 3.117 & 6.565 \\
\hline \multirow[t]{5}{*}{$15-$} & Remuneração da terra & 1.355 & 8.130 & 1.527 & 4.067 & 4.064 & 8.129 \\
\hline & SUB-TOTAL (C) & 1.355 & 8.130 & 1.527 & 4.067 & 4.064 & 8.129 \\
\hline & TOTAL DOS CUSTOS FIXOS $(\mathrm{B}+\mathrm{C})$ & 3.666 & 11.558 & 3.260 & 7.343 & 7.180 & 14.693 \\
\hline & CUSTO OPERACIONAL (A+B) & 58.653 & 39.150 & 15.188 & 27.793 & 19.588 & 40.840 \\
\hline & CUSTO TOTAL $(A+B+C)$ & 60.008 & 47.280 & 16.715 & 31.860 & 23.652 & 48.968 \\
\hline
\end{tabular}

Fonte: Elaborado pelos autores.

foram utilizados os valores obtidos anteriormente do custo médio total de cada produto e somaram-se os valores de todos os produtos ano a ano. Em seguida, como se procedeu metodologicamente com as receitas do projeto, corrigiu-se o valor do custo estimado para os próximos 10 períodos do projeto através da meta de inflação (IPCA) fixada pelo governo em $4,5 \%$, projetada para 2016, 2017 e 2018. (BCB, Resolução 4.499/16). Esta correção se faz necessária, pois o índice de inflação distorce o preço real dos produtos no País.

No primeiro período do projeto, o custo total estimado para viabilizar a diversificação é de $\mathrm{R} \$ 238.765$. Em seu quinto período, por exemplo, o custo total estimado alcança a marca de $\mathrm{R} \$ 284.732$. No décimo período, o custo total do projeto atinge $\mathrm{R} \$ 354.828$, apresentando uma evolução do crescimento médio em $150 \%$ ao longo dos 10 anos. Na Tabela 4, apresenta-se o custo total de cada cultura por período:

Após estimar o valor das receitas e despesas totais para o horizonte de 10 anos, o próximo passo é o de construir o fluxo de caixa do projeto. Este demonstrativo financeiro aponta a movimentação do fluxo de recursos financeiros alocados no projeto, como entradas ou saídas de caixa, e o resultado líquido em cada exercício sendo considerado lucro, em sinal positivo, ou prejuízo, com sinal negativo. Utilizou-se como referência a modalidade lucro presumido, com a alíquota de $20 \%$ sob o resultado presumido do exercício, conforme o art. 5 da Lei Federal 8.023/1990 (Brasil, 1990).

A evolução do resultado do saldo do período inicial até o período subsequente é denominada de fluxo de caixa líquido acumulado. Este saldo inicia-se em valor negativo, pelo desembolso de recursos de $-\mathrm{R} \$ 702.075$ no período zero para iniciar a operação. Este valor, somado ao fluxo de caixa do período 1, é de-R \$ 613.6074. Após, somando o valor anterior junto ao valor do fluxo de caixa do período 2, obtém-se o valor de-R $\$ 512.705$. Posto isso, é possível notar que, sucessivamente, o valor do fluxo de caixa neste projeto vai aumentando continuamente. Ao final do décimo período, o valor do fluxo de caixa líquido acumulado é de $\mathrm{R} \$ 834.345$. A Tabela 5 apresenta o fluxo de caixa do projeto: 
Tabela 4. Custo Total de cada cultura por período (em Reais)

\begin{tabular}{lcccccccccc}
\hline \multicolumn{1}{c}{ Produto } & Ano 1 & Ano 2 & Ano 3 & Ano 4 & Ano 5 & Ano 6 & Ano 7 & Ano 8 & Ano 9 & Ano 10 \\
\hline Café & 62.708 & 65.530 & 68.479 & 71.560 & 74.780 & 78.146 & 81.662 & 85.337 & 89.177 & 93.190 \\
Feijão & 49.408 & 51.631 & 53.955 & 56.383 & 58.920 & 61.571 & 64.342 & 67.237 & 70.263 & 73.425 \\
Mandioca & 17.467 & 18.253 & 19.075 & 19.933 & 20.830 & 21.767 & 22.747 & 23.770 & 24.840 & 25.958 \\
Milho & 33.294 & 34.792 & 36.358 & 37.994 & 39.704 & 41.490 & 43.358 & 45.309 & 47.348 & 49.478 \\
Soja & 24.716 & 25.829 & 26.991 & 28.206 & 29.475 & 30.801 & 32.187 & 33.636 & 35.149 & 36.731 \\
Trigo & 51.172 & 53.474 & 55.881 & 58.395 & 61.023 & 63.769 & 66.639 & 69.638 & 72.771 & 76.046 \\
Total Anual & $\mathbf{2 3 8 . 7 6 5}$ & $\mathbf{2 4 9 . 5 1 0}$ & $\mathbf{2 6 0 . 7 3 8}$ & $\mathbf{2 7 2 . 4 7 1}$ & $\mathbf{2 8 4 . 7 3 2}$ & $\mathbf{2 9 7 . 5 4 5}$ & $\mathbf{3 1 0 . 9 3 4}$ & $\mathbf{3 2 4 . 9 2 6}$ & $\mathbf{3 3 9 . 5 4 8}$ & $\mathbf{3 5 4 . 8 2 8}$ \\
\hline
\end{tabular}

Fonte: Elaborado pelos autores.

Tabela 5. Fluxo de caixa do projeto projetado para 10 anos (em Reais)

\begin{tabular}{|c|c|c|c|c|c|c|}
\hline Itens & Ano 0 & Ano 1 & Ano 2 & Ano 3 & Ano 4 & Ano 5 \\
\hline Investimento Inicial & -702.075 & & & & & \\
\hline (+) Receita Operacional & & 350.016 & 374.972 & 401.708 & 430.349 & 461.033 \\
\hline (-) Custo Operacional & & 238.765 & 249.510 & 260.738 & 272.471 & 284.732 \\
\hline (=) Lucro Operacional & & 111.251 & 125.462 & 140.970 & 157.878 & 176.301 \\
\hline (-) Imposto de Renda & & 22.250 & 25.092 & 28.194 & 31.576 & 35.260 \\
\hline (=) Fluxo de Caixa Líquido & -702.075 & 89.001 & 100.370 & 112.776 & 126.303 & 141.041 \\
\hline FC Líquido Acumulado/Valor Residual & -702.075 & -613.074 & -512.705 & -399.929 & -273.626 & -132.585 \\
\hline Itens & & Ano 6 & Ano 7 & Ano 8 & Ano 9 & Ano 10 \\
\hline (+) Receita Operacional & & 493.905 & 529.120 & 566.847 & 607.263 & 650.560 \\
\hline (-) Custo Operacional & & 297.545 & 310.934 & 324.926 & 339.548 & 354.828 \\
\hline (=) Lucro Operacional & & 196.360 & 218.186 & 241.920 & 267.715 & 295.733 \\
\hline (-) Imposto de Renda & & 39.272 & 43.637 & 48.384 & 53.543 & 59.147 \\
\hline (=) Fluxo de Caixa Líquido & & 157.088 & 174.549 & 193.536 & 214.172 & 236.586 \\
\hline FC Líquido Acumulado/Valor Residual & & 24.503 & 199.052 & 392.588 & 606.759 & 843.345 \\
\hline
\end{tabular}

Fonte: Elaborado pelos autores.

\subsection{Análise do projeto de diversificação pelos métodos tradicionais - VPL, TIR e Payback Simples}

Depois de estruturar o fluxo de caixa do projeto, procedeu-se com os cálculos dos métodos tradicionais da análise de investimento do projeto, para posteriormente comparar com os resultados obtidos pelo método das opções reais. Para efetuar os cálculos utilizou-se o software Microsoft Excel ${ }^{\circledR}$. A taxa de juros Selic no valor de $13,75 \%$ (com base em 30/11/2016) foi escolhida como parâmetro para ser a Taxa Mínima de Atratividade (TMA) do projeto, por ser uma taxa representativa para o investimento que está sendo considerado frente às oscilações do mercado.

O VPL do projeto nestas condições é de $\mathrm{R} \$ 24.673,00$, sugerindo que, ao final do último período, ele consegue se pagar, demonstrando valor positivo de $\mathrm{R} \$ 24.673,00$. Para sustentar esta hipótese, obteve-se o resultado da TIR em 14,5\%, ou seja, superior à Taxa Mínima de Atratividade (TMA) de 13,75\% do projeto - apontando a viabilidade de investimento pelos métodos tradicionais. O payback, ou período de retorno do projeto, é de 5 anos e 11 meses, que representa o período em que o projeto paga o investimento inicial e começa a obter lucro.

Os resultados obtidos apontam a viabilidade do projeto de investimento de diversificação na produção rural. Entretanto, este valor do VPL para análise tem inúmeros vieses, pois, primeiramente, considera que a TMA é estática; segundo, não considera valor da volatilidade (risco) do projeto, que é muito influenciado pelos preços das commodities; e, por fim, também não considera o valor das flexibilidades gerenciais que estão 
Figura 2. Árvore Binomial de Opções Reais do projeto de diversificação rural

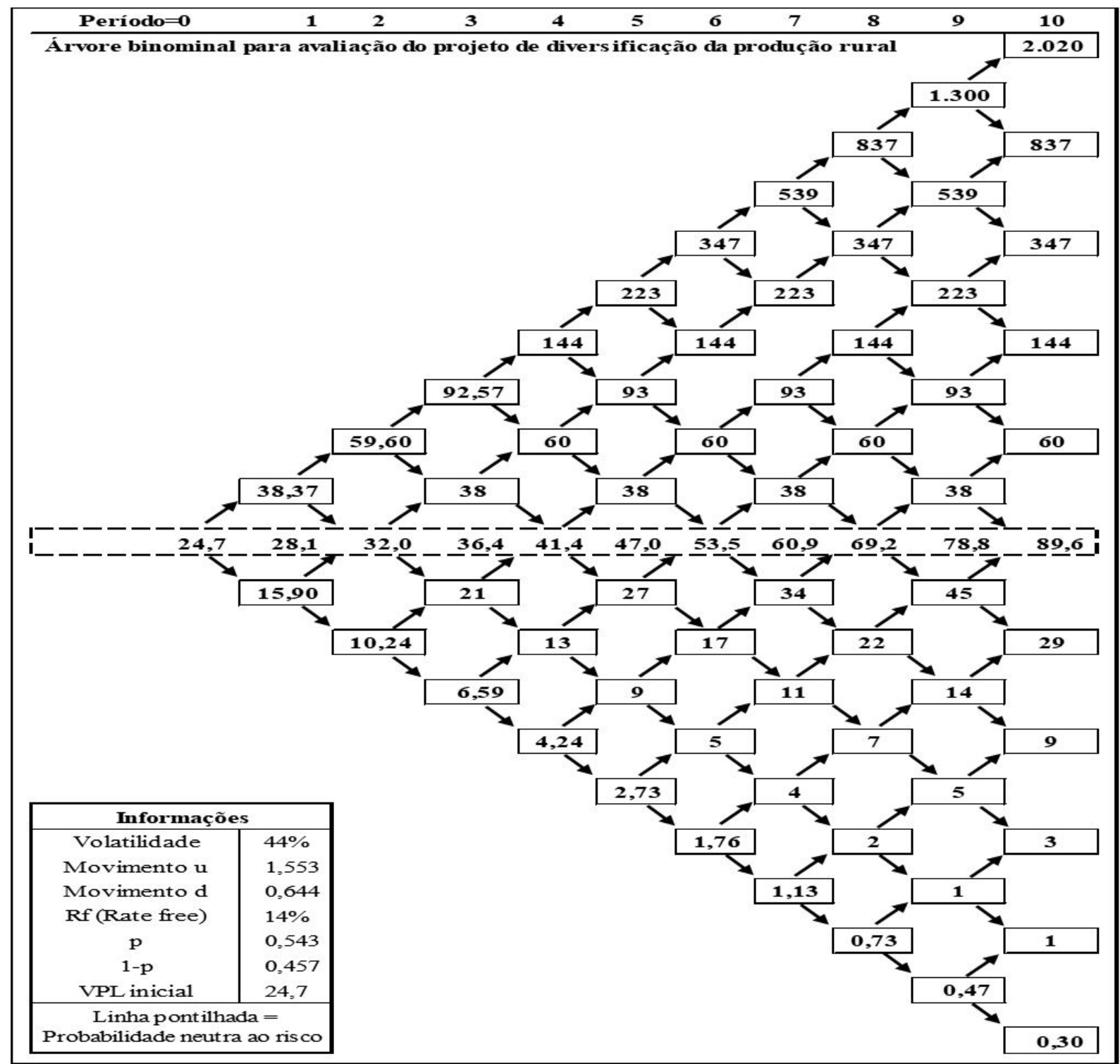

Fonte: Elaboração dos autores.

implícitas neste tipo de investimento, como as opções, por exemplo, de adiar ou expandir a produção de uma cultura ou até mesmo de vender parte da terra, que exercem forte influência nos fluxos de caixa do projeto.

\subsection{Análise do projeto de investimento de diversificação pela Teoria das Opções Reais}

A análise das opções do projeto de diversificação na produção rural utilizando o modelo binomial possibilita a captação do valor das opções reais em cada nó do modelo, identificando a captação das oportunidades de investimento que não são consideradas nos métodos de análise tradicionais (Nardelli \& Macedo, 2011). Para avaliar o projeto pelas opções reais, apresentamos as seguintes características:

- Investimento Inicial: R\$ 702.075,00;

- Valor Presente Líquido (VPL): R\$24.673,00;

- Número de períodos: 10 anos;

- $\quad$ Taxa de Juros (Rate free-RF): 13,75\% a.a. (TMA).

Para iniciar a construção da árvore binomial das opções reais, é necessário obter um valor de volatilidade 
da opção do projeto. Como não há referência histórica da volatilidade para este tipo de investimento, foi necessário utilizar uma medida de aproximação (Proxy) para estimá-la. Evangelista (2006) utilizou o preço da soja para calcular a volatilidade dos projetos de uma cooperativa de crédito. $\mathrm{O}$ autor calculou a volatilidade anual em bases semestrais, quadrimestrais, mensais e diárias no período de 2000 a 2004, com o preço em dólar, e definiu o valor do risco para analisar os projetos da cooperativa em $20 \%$. Neste estudo, a volatilidade da opção do projeto foi calculado com base no preço das seis culturas analisadas: café, feijão, mandioca, milho, soja e trigo. Para calculá-la, buscou-se o histórico do preço anuais das culturas na base de dados da Seab no período de 2006 a 2016, em Reais, e deflacionou-se a série através do índice IGP-M encontrada no sítio eletrônico da FGV, com base em 31/10/2016.

Em seguida, foi calculado o desvio padrão das séries e utilizada uma média ponderada para encontrar o resultado da volatilidade (risco) das seis culturas do projeto. O valor obtido foi de $44,04 \%$. Após encontrar a volatilidade, iniciou-se a construção da árvore binomial do projeto. As Fórmulas 1 a 5 utilizadas para achar as respostas ao modelo binomial para encontrar as opções reais, pela opção de venda americana, são mostradas a seguir:

- $\quad " \sigma "$ Volatilidade: $44,04 \%$;

- $\quad$ " $u$ " (movimento ascendente) $=1,11628$;

- $\quad$ "d" (movimento descendente) = 0,89583;

- Probabilidade neutra ao risco de um movimento ascendente: $0,542819391 \%$

- Probabilidade neutra ao risco de um movimento descendente, ou" q": 0,457180609\%;

- Taxa de Risco (Rf): 13,75\% a.a.

Para efeitos de simplificação matemática, dividiu-se por milhares (1.000) o valor do VPL e da Opção Real para construir a árvore binomial. Para construir os nós da árvore, multiplica-se o valor do VPL pelo valor do movimento ascendente ou descendente no período. O VPL inicia-se em R $\$ 24,7$ no período zero. O movimento ascendente para o primeiro período faz o VPL aumentar o seu valor para $\mathrm{R} \$ 38,37$. O movimento descendente do período zero para o primeiro faz o valor do VPL cair para $\mathrm{R} \$ 15,90$. A partir do primeiro período para o segundo, o movimento ascendente anterior pode tomar duas formas: ascender novamente, obtendo um VPL de R \$ 59,60; ou descender, trazendo o VPL novamente para a marca de
$\mathrm{R} \$ 31,96$. O movimento descendente do período zero para o primeiro segue o mesmo raciocínio do primeiro para o segundo: o valor do VPL ascende para R $\$ 41,96$ ou descende para R\$10,24. E assim, sucessivamente, constroem-se os nós da árvore binomial do VPL até o décimo período.

O modelo encontrado mostra que, dado um VPL de $\mathrm{R} \$ 24.700,00$ no período zero, o valor pode chegar até $\mathrm{R} \$ 89.600,00$ no período 10, a uma taxa livre de risco de $13,75 \%$. Porém, se considerarmos a volatilidade de $44,04 \%$ do projeto, que representa o risco da operação (volatilidade) baseado na média de preços das commodities estudadas, a cada período o VPL pode oscilar, e a árvore binomial indica que o valor da Opção Real encontrada pode chegar até $R \$ 2.019 .900,00$ no último nó ascendente, ou até $\mathrm{R} \$ 300,00$ no último nó descendente, incorporando o risco no retorno analisado Por outro lado, isto mostra que o administrador tem muitas possibilidades de obter ganhos adicionais durante a continuidade do projeto, dado a minimização do risco, e que pode arriscar flexibilizar as decisões gerenciais caso tenha interesse ao longo dos períodos, para saber se é interessante continuar, pausar, expandir ou abandonar o projeto. Diferente dos métodos tradicionais, o método da Opção Real incorpora a flexibilidade das decisões nas opções no cálculo do VPL, pois, assim, é possível tomar decisões incorporando o risco do projeto. A Figura 2 apresenta o modelo de árvore binomial aplicada no projeto de diversificação rural.

Estes resultados mostram que o método de opções reais pode ser de grande utilidade para a tomada de decisão do administrador rural com relação a projetos de diversificação da produção rural, dado que o método incorpora o risco em sua análise e a flexibilidade das decisões ao longo do tempo. Do mesmo modo, os estudos de Brennan \& Schwartz (2001), Moel \& Tufano (2002), Evangelista (2006) e Nardelli \& Macedo (2011) corroboram com tal conclusão. Da mesma forma que Brennan \& Schwartz (2001), fica claro que a análise da viabilidade de projetos envolvendo commodities necessita uma melhor avaliação que não inclua apenas o método do VPL tradicional, mas, sim, o integre com outros métodos como o das opções reais, pois permite representar as opções do gestor com mais fidedignidade. As decisões de investimento, conforme os resultados de Moel \& Tufano (2002), são mais assertivas quando consideram o modelo das opções reais, já que este 
instrumento permite avaliar as especificidades do projeto. Assim como chegou à conclusão Evangelista (2006), o VPL tradicional ainda permanece importante, sendo fundamental na determinação das opções reais, já que este método busca complementar e ampliar a análise de investimentos em projetos estudados pelo método do VPL tradicional. Por fim, este estudo também encontrou resultados diferentes para o valor das opções reais e o valor presente tradicional, corroborando com a pesquisa de Nardelli \& Macedo (2011).

\section{Considerações finais}

Este estudo objetivou analisar o impacto que a teoria das opções reais da análise de investimentos tem sobre a diversificação da produção rural. Assim, estabeleceu-se esta pesquisa como exploratória, através de procedimentos de uma pesquisa documental, abordando o problema de forma quantitativa, o que permitiu abordar e descrever os resultados de forma adequada, alcançando uma resposta ao problema de pesquisa.

A pesquisa foi delimitada como a análise de investimentos de uma produção agrícola de seis culturas diferentes em uma pequena fazenda na região oeste do estado do Paraná, cujo tamanho era de 24 hectares, em um horizonte temporal de análise de 10 anos. As culturas escolhidas foram a de café, feijão, mandioca, milho, soja e trigo. $\mathrm{O}$ investimento inicial total das operações foi de $\mathrm{R} \$ 702.075,00$, considerando máquinas e utensílios agrícolas. Realizou-se a projeção anual das receitas por cultura, bem como a projeção do custo total do período para cada uma das culturas. Assim, foi possível estabelecer os custos e investimentos necessários, evidenciado através do fluxo de caixa do projeto nos 10 anos seguintes.

Pelos métodos tradicionais de análise, percebeu-se que o VPL foi de R\$24.673,00, demonstrando resultado positivo, com lucro ao investidor. Obteve-se o resultado da TIR em 14,5\%, superior à taxa mínima de atratividade $(13,75 \%)$ do projeto. O período de retorno, calculado pelo payback simples, foi de cinco anos e 11 meses. Assim, pelos métodos tradicionais conclui-se que o projeto de investimento de diversificação rural seria viável, o payback demonstra retorno dentro do período delimitado e o VPL e a TIR se mostraram superiores ao parâmetro esperado. O VPL, no entanto, tem inúmeros vieses, pois considera a TMA estática, não considera o valor da volatilidade (risco), que é característica própria das commodities, e também não considera o valor das flexibilidades gerenciais que estão implícitas neste tipo de investimento.

Pelo método das opções reais, o modelo demonstra que dado um VPL inicial de R \$24,7 mil, o valor da Opção Real vai de R\$2.020.000 em sua amplitude máxima até R\$300,00 em sua amplitude mínima na árvore binomial, em função da volatilidade, taxa livre de risco utilizada e probabilidades utilizadas.

Dessa forma, conclui-se que os dois métodos geram diferentes tipos de análises, sendo o das opções reais o mais indicado por representar com maior fidedignidade a realidade do negócio. Assim, pode-se afirmar que os resultados deste estudo corroboram com os de Brennan \& Schwartz (2001), Moel \& Tufano (2002), Evangelista (2006) e Nardelli \& Macedo (2011).

Como este estudo buscou obter uma resposta sobre como a teoria das opções reais pode aprimorar a análise de investimentos na diversificação rural, tem-se que as técnicas de análise da viabilidade de projetos têm as suas particularidades em cada contexto, apresentando os seus pontos fortes e fracos dependendo do enfoque adotado. É notável a diferença entre as técnicas expostas anteriormente, sendo que o modelo tradicional de análise de investimentos considera o valor do dinheiro no tempo, mas desconsidera o valor das flexibilidades gerenciais e o risco do projeto. Enquanto isto, o modelo das opções reais incorpora o risco na análise e oferece uma visão mais ampla do caminho que o fluxo de caixa pode tomar através da árvore binomial, detalhando melhor a análise para a tomada de decisão.

Compreender as variações do VPL e a relação entre o risco e o retorno são fatores fundamentais para o gestor verificar se há a viabilidade e se ele está disposto a correr os riscos na decisão de iniciar e dar continuidade no projeto. O modelo de diversificação na produção rural apresenta-se como uma alternativa favorável e positiva ao pequeno produtor, pois ele dilui o risco do plantio ao diversificar culturas em uma área ao longo dos anos. Além disso, ele pode testar quais culturas se adaptam melhor ao seu solo e reduzir a perda em função do manejo ou de externalidades climáticas, por exemplo. $\mathrm{O}$ estudo de caso exposto corrobora esta visão, apresentando, através da árvore binomial, um fluxo positivo do VPL e do valor das Opções Reais ao longo dos períodos, na totalidade dos nós criados. 
Portanto, as contribuições dessa pesquisa não ficaram restritas ao ambiente prático, já que buscou realizar uma análise de investimentos sob a ótica do método das opções reais. Essa análise permitiu perceber a utilidade desse instrumento como ferramenta de análise de investimento sem projetos de diversificação da produção rural, assunto não explorado pelo método das opções reais. As contribuições para o campo acadêmico fortalecem a discussão da teoria das opções reais, possibilitando o uso desse estudo como referência nas próximas pesquisas.

Por fim, como o artigo ficou delimitado à análise das opções reais na diversificação rural, sugere-se, para estudos futuros, a utilização desta teoria em outras áreas e cenários econômicos, já que o modelo das opções reais busca refletir de forma mais adequada as especificidades de cada projeto. Portanto, considerar diferentes cenários econômicos e projetos de investimentos pode ser relevante na construção das próximas pesquisas.

\section{Referências}

Amram, M., \& Kulatilaka, N. (1999). Real options: managing strategic investment in an uncertain world. Boston: Harvard Business School.

Araújo, M. J. (2005). Fundamentos de agronegócios. São Paulo: Atlas.

Baiardi, A., \& Alencar, C. M. M. (2014). Agricultura familiar, seu interesse acadêmico, sua lógica constitutiva e sua resiliência no Brasil. Revista de Economia e Sociologia Rural, 52, 45-62.

Balarine, O. F. O. (2004). The use of appraisal techniques in property development. Production, 14(2), 47-57.

Batalha, M. O. (2005). Gestão do agronegócio - textos selecionados. São Carlos: EdUFCAR.

Beuren, I. M. (2009). Como elaborar trabalhos monográficos em contabilidade (3. ed.). São Paulo: Atlas.

Black, F., \& Scholes, M. (1973). The pricing of options and corporate liabilities. Journal of Political Economy, 81(3), 637-654.

Brasil, H. G., Aronne, A., \& Rajão, A. (2011, june 1518). Valuation of the options to expand and verticalize a fertilizer investment. In Proccedings of the Annual International Conference on Real Options (pp. 1-16). Finland: Real Options Group.

Brasil. (1990, abril 12). Lei 8.023 de 12 de abril de 1990. Altera a legislação do Imposto de Renda sobre o resultado da atividade rural, e dá outras providências. Diário Oficial da União, Brasília.

Brennan, M. J., \& Schwartz, E. S. (2001). Evaluating Natural Resource Investments. In E. S. Schwartz, \& L. Trigeorgis (Orgs.), Real Options and Investment Under Uncertainty: classical reading and recent contributions. Massachusetts: MIT Press. Cap.16.

Callado, A. A. C., \& Callado, A. L. C. (1999, junho-julho 29-02). Custos: um desafio para a gestão no agronegócio. In Anais do Congresso Brasileiro de Custos (pp. 1-12). São Paulo: Associação Brasileira de Custos.

Casarotto Filho, N., \& Kopittke, B. H. (2000). Análise de investimentos (9. ed.). São Paulo: Atlas.

Crepaldi, S. A. (1993). Contabilidade rural. São Paulo: Atlas.

Copeland, T. E., \& Antikarov, V. (2001). Opções reais: um novo paradigma para reinventar a avaliação de investimentos (Trad. Maria José Cyhlar Monteiro). Rio de Janeiro: Campus.

Davis, J. H., \& Goldberg, R. A. (1957). A concept of agribusiness. Boston: Harvard University.

Dixit, A. K., \& Pindyck, R. S. (2001). The options approach to capital investment. In E. S. Schwartz, \& L. Trigeorgis (Orgs.), Real Options and Investment Under Uncertainty: classical reading and recent contributions (cap. 5). Massachusetts: MIT Press.

Evangelista, M. L. S. (2006). Estudo Comparativo de Análise de Investimentos em Projetos entre o Método VPL e o de Opções Reais: O Caso Cooperativa de Crédito - Sicredi Noroeste (Tese de doutorado). UFSC, Florianópolis.

Franco, H. (1988). Contabilidade industrial (8. ed.). São Paulo: Atlas.

Gitman, L. J. (2010). Princípios de administração financeira (12 ed.). São Paulo: Pearson Prentice Hall.

Gil, A. C. (2009). Didática e metodologia do ensino superior. São Paulo: Atlas.

Hull, J. (1996). Introdução aos mercados futuros e de opções (2. ed. rev. ampl.). São Paulo: Bolsa de Mercadorias \& Futuros.

Instituto Paranaense de Desenvolvimento Econômico e Social - IPARDES. (2016). Paraná em números. Curitiba: Ipardes. Recuperado em 22 dez. 2016, de http: / / www. ipardes.pr.gov.br

Macedo, M. A. S., \& Nardelli, P. M. (2008, julho 20-23). Utilizando opções reais na análise de viabilidade de Projetos de investimento agropecuários: um ensaio teórico. In Anais do $46^{\circ}$ Congresso da Sociedade Brasileira de Economia, Administração e Sociologia Rural (pp. 1-21). Rio Branco: SOBER.

Moel, A., \& Tufano, P. (2002). When are real options exercised? An empirical study of mine closings. Review of Financial Studies, 15(1), 35-64. 
Mondher, B. (2002, junho 6). Extended DCF analysis and real options analysis within Information uncertainty: applications for project valuation and R\&D. In Proceedings of The International Annual Conference On Real Options (cd-rom). Paphos: Real Options Group.

Myers, S. C. (1987). Finance theory and financial strategy. Midland Corporate Finance Journal, 5(1), 6-13.

Nardelli, P. M., \& Macedo, M. A. S. (2011). Análise de um projeto agroindustrial utilizando a Teoria de Opções Reais: a opção de adiamento. Revista de Economia e Sociologia Rural, 49(4), 941-966.

Paraná. (2016). Valor bruto da produção agropecuária paranaense em 2016. Curitiba: Seab. Recuperado em 04 abr. 2016, de www.pr.gov.br/seab

Pelinski, A., Ahrens, D. C., Milléo, R. D. S., Zemke, E., Benassi, D. A., \& Richter, A. S. (2006). A diversificação no incremento da renda da propriedade familiar agroecológica. In Anais do Congresso Brasileiro de Agroecologia (pp. 1-4). Londrina: IAPAR.

Priori, A., Pomari, L. R., Amâncio, S. M., \& Ipólito, V. K. (2012). A modernização do campo e o êxodo rural. In A. Priori, L. R. Pomari, S. M. Amâncio, \& V. K. Ipólito. (Orgs.), História do Paraná: séculos XIX e XX (pp. 115-127). Maringá: Eduem.
Ross, S. A., Westerfield, R. W., \& Jordan, B. D. (1998). Princípios de administração financeira: essentials of corporate finance. São Paulo: Atlas.

Richetti, A. (2006). O que é diversificação agropecuária. Revista Campo E Negócios, 42, 70-70.

Schuch, H. J. (2004). A importância da opção pela agricultura familiar. Porto Alegre: FETAG.

Sousa Neto, J. A., Oliveira, V. I., Bergamini Junior, L. C. (2008). Opções reais: introdução à teoria e à prática. Rio de Janeiro: Qualitymark.

Trigeorgis, L. (2002). Real options: managerial flexibility and strategy in resource allocation (6th ed.). Massachusetts: MIT Press.

Trigeorgis, L., \& Mason, S. P. (1987). Valuing managerial flexibility. Midland Corporate Finance Journal, 5(1), 14-21.

Valle, F. (1985). Manual de contabilidade agrária. São Paulo: Atlas.

Weston, J. F., \& Brigham, E. F. (2000). Fundamentos da administração financeira (10. ed.). São Paulo: Makron Books.

Zilio, L. B., \& Lima, R. A. S. (2015). Atratividade de canaviais paulistas sob a ótica da Teoria das Opções Reais. Revista de Economia e Sociologia Rural, 53(3), 377-394. 